\title{
O DESMANTELAMENTO DA CIENNCIA BRASILEIRA NO DELIBERADO \\ CORTE DE BOLSAS: ASPECTOS POLÍTICOS E CONSEQUENNCIAS PSICOSSOCIAIS PARA ESTUDANTES DE PÓS-GRADUAÇÃO
}

Ana Carolina Reis Breno Alves dos Santos Blundi Eduardo Pinto e Silva

RESUMO:O presente artigo visa, com base numa compreensão do contexto econômico e político nacional e, em pressupostos do campo marxista, analisar o processo de desmantelamento da ciência por meio da portaria 34 de 9 março de 2020, proposta pela CAPES, que visa o corte de bolsas de pesquisas destinadas a programas e estudantes da pós-graduação brasileira. Os dados analisados são oriundos da portaria supracitada e das respostas de 72 estudantes da Universidade Federal do Paraná (UFPR) das três grandes áreas do conhecimento (Ciências Exatas; Biológicas e Humanas) coletadas através de um questionário online. $\mathrm{O}$ artigo aponta que, além prevalecer uma política de negação da ciência, são engendrados processos psicossociais que se deslizam dos efeitos econômicos e impedimentos dos projetos acadêmicos-profissionais dos estudantes, para sua saúde e subjetividade, com destaque para o estresse e sofrimento psíquico que, em alguns casos, redundou em sintomas depressivos e até mesmo em ideação suicida.

PALAVRAS-CHAVE: Educação. Política da educação. Financiamento da ciência. Aspectos Psicossociais. Portaria 34.

\section{INTRODUÇÃo}

As mudanças advindas do mundo do trabalho, isto é, substituição do binômio fordismo-keynesianismo pelo toyotismo, juntamente com a reestruturação produtiva do capital, estabeleceu relações homem-trabalho cada vez mais flexíveis e transformações significativas nos aspectos funcionais da forma política do Estado (MASCARO, 2013), o que propiciou um deslocamento da figura de provedor de direitos para regulador da economia. Tais características possuem ligação direta no estabelecimento de prioridades de financiamento de desenvolvimento de políticas. E, no que o presente artigo se propõe a discutir, daquelas de fomento à ciência e tecnologia $(C \& T)$, mormente em comparação às das ciências humanas. $E$ ainda, o processo de desenvolvimento de documentos políticos correspondentes, e os desdobramentos psicossociais e políticos para os atores envolvidos com a produção científica no país.

O cenário de incentivo à ciência no parâmetro nacional, alinhado com todas as contradições ali inseridas, se transfigurou de um cenário progressivo para um cenário de retrocesso. A exemplo do posto, ilustra-se que o ano de 2013 contabilizou o maior pico de investimentos em C\&T, quando comparado com os anos que sucederam 2003. Em contraposição, 2020 é marcado pelo processo de retração de investimentos, fato este que é expresso na diminuição de 55,04\% do orçamento quando comparado com a estimativa de gastos de 2013 (MACÁRIO; REIS, 2020).

No bojo dessas transformações, tem-se como possíveis desdobramentos o enfraquecimento do sistema de manutenção de pesquisa/produção de conhecimento; a ampliação dos cortes de bolsas de pesquisa e, respectivamente, a interrupção de pesquisas, ora em andamento, em decorrência da escassez de recursos materiais. Ademais, o cenário ganhou novos contornos com o novo modelo de concessão de bolsas da CAPES, oriundo das portarias: $\mathrm{n}^{\circ} 18$ e 20 , de 20 de fevereiro de 2020, $\mathrm{n}^{\circ} 21$, de 26 de fevereiro de 2020 e, principalmente, $\mathrm{n}^{\circ} 34$, de 9 de março de 2020.

Contudo, cabe frisar que o modelo citado não se esgota em si mesmo. Ele faz parte, e será passível de tratamento de análise como tal, enquanto um dos elementos que se encontra engen- 
drado num amplo processo jurídico-político que visa, em última instância, a intensificação e avanço do modelo neoliberal na produção de conhecimento. O desmantelamento da ciência também reforça a lógica colonizadora que faz com que o Brasil mantenha o status de exportador de matéria prima, assim como a ideia de um país que se mantém incapaz de sair do subdesenvolvimento.

Nesse sentido, convém enfatizar, primordialmente, a necessidade de pautar o sucateamento da produção científica para além dos números que a legitimam. Ela não advém somente dos movimentos que fazem com que os recursos de sua manutenção se apresentem escassos, mas sim da própria forma de acumulação do capital e da postura dos agentes que o sustentam - trabalhadores, capitalistas, Estado, agentes econômicos, empresas públicas e privadas, entre outros.

"Um sistema particular de acumulação pode existir porque o sistema de reprodução é coerente" (HARVEY, 1992, p. 117). Tal coerência torna-se realizável a partir da interiorização de grande parte dos atores políticos no que diz respeito à sua função na reprodução daquele sistema. É necessário, portanto, colocar, em primeiro momento, o Estado em evidência, tratando-o como um elemento histórico-filosófico e fundamental para a sustentação de formas de acumulação. Lipietz (1986) discorre sobre as condições propícias de implementação e sequência de um regime de acumulação:

Uma materialização do regime de acumulação, que toma a forma de normas, hábitos, leis, redes de regulamentação, etc; que garantam a unidade do processo, isto é, a consciência apropriada entre comportamentos individuais e o esquema de reprodução. Esse corpo de regras e processos sociais interiorizados tem o nome de modos de regulamentação. (LIPIETZ, 1986, p. 19).

O Estado é, portanto, uma parte primordial para a reprodução capitalista e para as formas de sociabilidade que a legitima. Ele opera num esquema de manutenção indireta, na dominância de uma classe em detrimento de outra a partir do apaziguamento dos conflitos de classe, característica pela qual acaba por assegurar a hegemonia do capital. O neoliberalismo, nesse cenário, aparece como um ideal de conduta em que membros da sociedade devem ser empresários de si, fazendo cair a responsabilidade sobre os indivíduos. Nesse sentido, o Estado internaliza novos modos de ação e legítima padrões de socialização que sejam harmonizados com tal lógica, estabelecendo, por meio de um conjunto jurídico-político, o medo enquanto afeto político (SAFATLE, 2015) e a conformidade em relação à experimentação de desamparo das políticas sociais.

Conduzido pelos moldes neoliberais, o aparato estatal passa a ser reduzido pela técnica e conduzido pela hegemonia das questões econômicas em detrimento das questões sociais. A Reforma do Estado citada, iniciada na década de 90, inaugurada pelo governo FHC, ainda que com avanços progressistas, e contradições, foi continuada pelo lulismo por meio da política conciliatória. A crise de 2008, juntamente com as rupturas derivadas dela, fornece novas tendências e regulações à ação estatal que dão margem para o avanço da submissão ao mercado financeiro. O cenário assume características mais perversas no governo Temer e Bolsonaro, representados por uma sintonia fina entre conservadorismo e ultra neoliberalismo.

Mancebo, Santorum, Ribeiro et al (2020) situa as principais consequências desse cenário:

A reforma do Estado, fazendo-o deixar espaço para o capital financeiro e oferecer o fundo público a este tipo de capital; (2) o congelamento de gastos com educação, saúde e assistência, de um modo geral; (3) a privatização, desregulamentação e desnacionali- 
zação dos sistemas públicos e de significativas empresas do Estado, como a Petrobrás, a Eletrobrás, a Caixa Econômica, o Banco do Brasil e a Casa da Moeda, dentre outras; (4) o aprofundamento da subordinação passiva à globalização capitalista, em especial, à alinhada aos interesses norte-americanos e (5) a redução fantástica do custo do trabalho vivo, com a devastação da legislação social protetora do trabalho, de que é prova a legislação aprovada no período. (MANCEBO; SANTORUM; RIBEIRO; et al, 2020, p. 6).

Esse contexto faz, ademais, retomar a discussão sobre até que ponto o Estado é autônomo em suas decisões, no sentido de que suas ações são autorizadas em função da reprodução capitalista. Isso não é diferente no âmbito do financiamento em ciência e tecnologia, haja vista o conjunto de pesquisas que nomeiam a aproximação do conhecimento ao processo de valoração capital. Essa articulação entre as duas últimas faz surgir determinadas formas de controle/exclusão, por meio de sistemas avaliativos (SANTANA, 2018), que buscam, incessantemente, tornar o subfinanciamento como um fator inexorável, intensificar a competitividade entre programas de pós-graduação num cenário de indisponibilidade de recursos e, respectivamente, justificar a escassez e desigualdades de investimentos no setor de ciência e tecnologia, responsabilizando os programas pelo próprio fracasso.

A crise da ciência advém da própria lógica flexível e dos modos de funcionamento do capitalismo financeiro. A ciência passa a ter legitimidade apenas quando alimenta o capital (MACÁRIO; REIS, 2020) desembocando na produção de repercussões excludentes e um conjunto de violências implícitas para os agentes que trabalham com a produção de conhecimento.

Nesse mesmo viés, foi desenvolvido, a partir do Pacto de Bolonha (1999), uma nova concepção de produção do conhecimento científico que, influenciou fortemente os novos rumos que a Coordenação de Aperfeiçoamento de Pessoal de Nível Superior (CAPES) passou a adotar no Brasil, principalmente no que tange à avaliação institucional dos programas de pós-graduação (PG), forjando novas exigências pautadas por pilares produtivistas, de modo a conciliar as determinações do Pacto com a tendência americana do "publish or perish" (publique ou pereça). E, mais do que isso, à rentabilidade que poderia ser derivada da produção científica e tecnológica.

A reestruturação dos programas de pós-graduação sob essas novas exigências, não atingiria somente as Instituições de Ensino Superior (IES), mas também, os coordenadores de programas de pós-graduação, os professores e, principalmente, os pós-graduandos, que são sujeitados a se preocupar com índices, classificações, fatores de impacto, rankings, publicações, e a lidar com situações que envolvem um grande grau de competição entre os programas e entre os próprios pós-graduandos (BIANCHETTI; VALE, 2014).

Com base nos pressupostos acima mencionados, apresentamos a seguir os resultados de uma pesquisa bibliográfica e documental, com destaque à análise das portarias de 2020 que versam sobre a concessão de bolsas de mestrado e doutorado, sendo: $\mathrm{n}^{\circ}$ 18, 20, 21 e, principalmente, $\mathrm{n}^{\circ} 34$, publicadas pela CAPES.

Buscamos, além da análise documental, compreender os impactos psicossociais e políticos que essas portarias acarretam na vida dos estudantes de pós-graduação da Universidade Federal do Paraná (UFPR). A escolha da UFPR como local de coleta de dados se deu pelo fato de ser uma universidade com significativo impacto de formação em nível de graduação e pós-graduação, notoriamente reconhecido estadual, nacional e internacionalmente. A UFPR possui mais de 60 programas de pós-graduação com notas superior a 3, que são contemplados com bolsas 
CAPES. A crítica à política de cortes assim é complementada pela análise dos seus impactos psicossociais para estudantes de pós-graduação. Tal se realizou por meio de coleta de dados através de um questionário aplicado a esses estudantes da UFPR, como explicitamos na seção seguinte.

Nesse sentido, as questões que nortearam o desenvolvimento da pesquisa se centram nas seguintes indagações: Sobre o que versam as Portarias lançadas pela CAPES acerca da concessão de bolsas? Qual a relação entre a dinâmica do produtivismo acadêmico e o desenvolvimento das portarias? Qual o impacto psicossocial e político que a implementação dessa nova política de concessão de bolsas causa nos estudantes de mestrado e doutorado?

Para responder a essas perguntas realizamos a análise do conceito do produtivismo acadêmico, principalmente através dos estudos de Sguissardi e Silva Júnior (2009), Bianchetti (2009), Bianchetti e Machado Neto (2007), Bianchetti e Valle (2014), dentre outros. As demais análises serão realizadas com base nos documentos das portarias e nas respostas coletadas através de questionário aplicado aos alunos de pós-graduação da UFPR. As análises macrossociais se fundamentam no método do materialismo histórico-dialético, e as psicossociais recorrem a conceitos desenvolvidos pela Psicodinâmica do Trabalho (DEJOURS, 2008; 2006; 2004).

Diante do exposto, o artigo foi organizado em quatro seções. Na primeira seção explicitamos a metodologia de levantamento de dados e o método de suas análises. $\mathrm{Na}$ segunda abordamos o fenômeno do produtivismo acadêmico, de modo a explicar o fenômeno em sua totalidade, o que nos subsidia o pano de fundo das análises das portarias. Na terceira seção apresentamos os resultados realizados a partir dos estudos das portarias lançadas pela CAPES. E na quarta seção apresentamos os resultados obtidos pelo questionário aplicado nos alunos de mestrado e doutorado da UFPR.

\section{Metodologia de levantamento de dados e método de ANÁlise}

A UFPR possui 69 programas de pós-graduação em nível acadêmico (mestrado e doutorado). Para realizar a coleta de dados dividimos os cursos em três grandes áreas: a) humanas; b) biológicas; c) exatas, distinguindo o ano de abertura do mestrado, do doutorado e o conceito do programa junto à CAPES.

Posteriormente elegemos ao total 11 programas de pós-graduação: 4 programas de exatas e biológicas - notas 4, 5, 6 e 7 - e 3 de humanas - notas 4, 5 e 6 . Os programas notas 3 não foram selecionados para essa pesquisa pelo fato da difícil concessão de bolsas pela CAPES para os mesmos. Visando manter a lisura e evitando o conflito de interesses, a seleção dos programas ocorreu por meio de sorteio eletrônico, através do site: https://www.sorteiogo.com/pt/sorteio/ nomes, dessa forma foram sorteados os seguintes programas:

Tabela 1

\begin{tabular}{|c|c|}
\hline \multicolumn{2}{|c|}{ RESULTADO DO SORTEIO } \\
\hline \multicolumn{2}{|c|}{ CIÊNCIAS BIOLÓGICAS } \\
\hline CONCEITO 4 & GENÉTICA \\
\hline CONCEITO 5 & ZOOLOGIA \\
\hline CONCEITO 6 & ECOLOGIA E CONSERVAÇÃO \\
\hline CONCEITO 7 & CIÊNCIAS (BIOQUÍMICA) \\
\hline & CIÊNCIAS EXATAS \\
\hline CONCEITO 4 & \\
\hline
\end{tabular}




\begin{tabular}{|c|c|}
\hline CONCEITO 5 & MATEMÁTICA \\
\hline CONCEITO 6 & FÍSICA \\
\hline CONCEITO 7 & QUÍMICA \\
\hline \multicolumn{2}{|c|}{ CIÊNCIAS HUMANAS } \\
\hline CONCEITO 4 & PSICOLOGIA \\
\hline CONCEITO 5 & HISTÓRIA \\
\hline CONCEITO 6 & DIREITO \\
\hline CONCEITO 7 & NÃO POSSUÍ \\
\hline
\end{tabular}

Tabela demonstrativa dos cursos sorteados. Tabela criada pelos autores.

Após o sorteio entramos em contato via e-mail com a secretaria de cada um dos programas. Nos apresentamos, esclarecemos o motivo do contato, apresentamos os objetivos da pesquisa e solicitamos que enviassem o questionário por meio do e-mail institucional a todos os mestrandos e doutorandos daquele programa. Informamos as secretarias e solicitamos que informassem aos pós-graduandos que o questionário permaneceria aberto por 15 dias e, após esse período, o mesmo seria encerrado automaticamente para fins de avaliação dos resultados. O questionário foi desenvolvido e divulgado por meio da plataforma eletrônica Survio: Pesquisa Online. A fim de assegurar a validade dos dados coletados, iremos explicitar como fundamentamos e o teorizamos para a aplicação do questionário nos alunos de pós-graduação da UFPR e, posteriormente, o método de análise dos dados.

Levando em consideração o objetivo central da pesquisa, a metodologia eleita para a coleta de dados é ancorada na perspectiva da amostragem não probabilística com ênfase na amostragem intencional por julgamento, uma vez que delimitamos como ponto de coleta de dados os pós-graduandos de 11 Programas de Pós-Graduação da Universidade Federal do Paraná.

A exposição das análises dos dados coletados será organizada de duas maneiras distintas. As questões fechadas com múltipla escolha, serão organizadas por meio da estatística descritiva "cujo objetivo básico é o de sintetizar uma série de valores da mesma natureza, permitindo dessa forma que se tenha uma visão global da variação desses valores" (DE FARIAS, s/a, p.1) organizando e descrevendo os dados através de: a) tabelas; b) gráficos; c) medidas descritivas. Já as questões abertas, com respostas discursivas, serão organizadas conforme a metodologia do Discurso do Sujeito Coletivo (DSC), que possui como intenção "reconstruir, com pedaços de discursos individuais, como um quebra-cabeça, tantos discursos-síntese quantos se julgue necessários para expressar uma dada 'figura', ou seja, um dado pensar ou representação social sobre um fenômeno" (LEFÈVRE; LEFÉVRE, 2005, p. 19).

Para a análise dos dados coletados, as revisões bibliográficas e documentais, isto é, para tecer as considerações finais, nos basearemos nos pressupostos do método marxista de análise: o materialismo histórico-dialético aplicado às análises de políticas educacionais, tal como explicitado por Masson (2007).

Nesse sentido, visando uma análise que denuncie as opressões geradas por instrumentos do capitalismo para a sua manutenção e exploração de indivíduos, em nosso caso, de pós-graduandos, objetivadas em políticas de concessão/cortes de bolsas, adotamos o materialismo histórico-dialético como pressuposto teórico para realizar as análises e as articulações entre as exposições. 


\section{O FENÔMENO DO PRODUTIVISMO ACADÊMICO E SUAS MÚLTIPLAS SÍNTESES NA SOCIEDADE ACADÊMICA DA CONTEMPORANEIDADE}

Nessa seção do artigo, nos preocupamos em analisar o fenômeno do produtivismo acadêmico em suas múltiplas sínteses, isto é, em sua totalidade, nos preocupando em analisar suas interfaces políticas, sociais, econômicas e acadêmicas, focalizando, principalmente, em analisar a lógica produtivista que os pesquisadores de pós-graduação das Instituições de Ensino Superior (IES) estão submetidos na atualidade e o consequente processo de intensificação do seu trabalho enquanto pesquisador.

Biachetti e Valle (2014) ao analisar a constituição do produtivismo acadêmico enquanto um fenômeno de opressão social, chegaram ao cerne de seu desenvolvimento. Para esses autores, a lógica produtivista, no âmbito acadêmico, se iniciou logo após o denominado Pacto de Bolonha de 1999. Pacto esse que se objetivava em um documento assinado por ministros da educação dos países participantes da União Europeia (UE) que visava a realização de ações de reestruturação do ensino superior dos países da UE, com o objetivo principal de promover e elevar a competitividade nacional e internacional do sistema europeu de ensino superior.

O Pacto de Bolonha possui como objetivo central a construção em um horizonte de 10 anos de um denominado Espaço Europeu de Ensino Superior (EEES) harmônico, coeso, atrativo e competitivo, com uma finalidade genérica e ilusória de promover uma mobilidade entre os estudantes e demais agentes educativos, bem como a empregabilidade de diplomados. Visando, dessa maneira, reforçar uma maior competitividade internacional entre os sistemas de ensino superior europeu em um contexto de globalização desses sistemas e da formação dos discentes e pesquisadores.

Para o ano de 2010, o Pacto de Bolonha previa um aligeiramento da graduação, mestrado e doutorado, encaminhando-se em ciclos que se concretizavam em três, dois e três anos, respectivamente. Para Bianchetti e Valle (2014), seria o alcance desse aligeiramento que garantiria uma maior flexibilização dos percursos de formação, isto é, a mobilidade entre estudantes prevista no Pacto desenvolvida concomitantemente com a empregabilidade de diplomados e com o reforço da competitividade internacional formaria, dessa forma, um tripé que assenta as principais asserções de uma política pública transnacional de organização das IES, ditando regras de como as mesmas devem desenvolver o trabalho na graduação e na pós-graduação.

Quase que simultaneamente ao processo de desenvolvimento do Pacto de Bolonha, no Brasil, a partir da década de 1990, a Coordenação de Aperfeiçoamento de Pessoal de Nível Superior (CAPES) acabou por sofrer influências do Pacto juntamente com a tendência americana do "publish or perish" (publique ou pereça), sendo a última uma das mais determinantes na CAPES que influenciou fortemente o novo modelo que conduziria a Pós-Graduação (PG) brasileira. Entretanto, a PG reestruturada sob essas novas exigências, não atingiria somente as IES, mas também, os Coordenadores de Programas de Pós-Graduação, os professores e, principalmente, os pós-graduandos, que são sujeitados, segundo Bianchetti e Vale (2014), a se preocupar com índices, classificações, fatores de impacto, rankings, publicações e a lidar com situações que envolvem um grande grau de competição entre os Programas e entre os próprios pós-graduandos.

Nessa perspectiva, a predominância do quantitativo sobre o qualitativo passa a interferir na produção científica, contribuindo para o denominado "produtivismo acadêmico" (SGUISSARDI; SILVA JUNIOR, 2009; BIANCHETTI, 2009). Dessa forma, Bianchetti e Machado 
(2007), identificaram três aspectos de grande impacto do produtivismo nas pesquisas científicas, isto é, três fenômenos que transformam as pesquisas em mercadorias, submetendo a produção científica às necessidades técnicas do capital. São eles:

a) O desenvolvimento de um senso comum acadêmico de que uma publicação equivale à uma descoberta científica de grande impacto;

b) O não questionamento dos impactos sociais que essa publicação acarreta, por exemplo, a falta do seguinte questionamento próprio: que efeitos positivos essa publicação gera para a humanidade?

c) Uma falta de rigor nas publicações, justificado por uma cultura, segundo Biachentti e Machado (2007), de "contabilidade", desenvolvida através do fenômeno do produtivismo acadêmico.

A política de produtivismo causa outro fenômeno entre os pesquisadores, a diminuição de lançamento de livros, uma vez que esses demandam mais tempo de reflexão e escrita, diminuindo assim a produtividade do autor, pois o mesmo terá que dispor de mais tempo refletindo o mesmo objeto de estudo. Ou seja, enquanto se publica um livro, pode-se publicar quatro ou mais artigos, sendo mais "rentáveis" nas avaliações e contagem de produtos finais. Portanto:

Recolocar o porquê, o para quê e para quem escrevemos e publicamos é urgente. Firmar posição de que o tempo do capital não pode subsumir os tempos da universidade nem da vida/trabalho é fundamental. Manter acesa a luta para fazer valer que "a escola [e a Universidade] não é uma empresa" (BIANCHETTI; MACHADO, 2007, p. 13, grifos dos autores).

Nesse sentido, nos vemos em um tempo histórico que a reflexão do motivo das publicações é necessária, isto é, estamos publicando para que estes trabalhos sejam expostos para a sociedade ou somente para aumentar os pontos nas avaliações e conseguir captar mais recursos? Ou ainda, no caso de alunos de pós-graduação, ter um currículo minimamente aceitável para submeter-se aos processos de outras etapas da pós-graduação ou em concursos das IES?

Segundo Domingues (2013), em meio à cultura do produtivismo e de índices altamente quantitativos, existem pesquisadores que, para garantir uma boa avaliação ou mais financiamento para suas pesquisas, trabalham se apropriando de estratégias nada éticas, como por exemplo, a publicação de artigos científicos "cuja elaboração, execução e redação não se teve uma participação efetiva” (DOMINGUES, 2013, p. 195). Segundo Garcia, Martrucelli et. al. (2010), embora esta prática seja tão comum quanto o plágio, não há punição, considerando o pesquisador que o faz apenas como um "mal profissional".

Domingues (2013) ressalta que, em 2011, o Comitê de Ética do Conselho Nacional e Desenvolvimento Científico e Tecnológico (CNPQ) estruturou um relatório sobre boas condutas em pesquisa, o qual, entre todas as questões, possui uma seção reservada para "a autoria de artigos científicos". Segundo o autor (ibidem), esse relatório considera autor quem presta uma contribuição significativa à pesquisa, participando de discussões, análises de dados, redação, revisão, fundamentação teórica e, devendo ainda, serem capazes de explicar e descrever a sua contribuição para tal pesquisa. Ademais, todos os coautores devem ser responsáveis pelas infor- 
mações expressas no artigo, capítulo, jornal ou livro publicado. O relatório, segundo Domingues (2013) não deixa margens para dupla interpretação para o que seja "contribuição":

\begin{abstract}
Por contribuição significativa entende-se realização de experimentos, participação na elaboração do planejamento experimental, análise de resultados ou elaboração do corpo do manuscrito. Empréstimos de equipamentos, obtenção de financiamentos ou supervisão geral, por si só não justificam a inclusão de novos autores, que devem ser objetos de agradecimento (CNPq, 2011, p. 6 apud DOMINGUES, 2013, s/p).
\end{abstract}

Embora conste no Relatório do CNPq informações claras de quem deve ou não entrar como autor de pesquisas, Garcia, Martrucelli et. al. (2010) chamam a atenção para pressões que orientandos e orientadores recebem dos Programas de Pós-Graduação para que, por exemplo, em nível de teses de doutorado, o orientador entre como autor na publicação da objetivação final da pesquisa para que, assim, eleve a avaliação do Programa, conseguindo futuramente mais bolsas e mais financiamento para as pesquisas.

Para Vosgerau, Orlando e Meyer (2017), a formação acadêmica e a produção científica se sobrepõem à formação didático-pedagógica dos docentes do ensino superior, fato este que explicita que o perfil do pesquisador passa a ser o condutor da qualidade da educação superior. Para o professor universitário, o conhecimento pedagógico passa a ser secundário em relação ao domínio de sua especialidade, afinal, é da pesquisa que vem um dos principais financiamentos das universidades. Dessa maneira, o produto da educação superior se sobrepõe aos processos, fazendo da pesquisa o principal componente do reconhecimento docente (CUNHA; ZANCHET; RIBEIRO, 2013, apud VOSGERAU; ORLANDO; MEYER, 2017).

Sguissardi e Silva Junior (2009) afirmam que, na prática, tais critérios promovem uma escala hierárquica de valorização em relação às atividades-fim da universidade: pesquisa, ensino (pós-graduação e depois graduação) e extensão. Na pós-graduação, essa escala de valor prioriza a publicação de artigos (mesmo que em forma de resultados preliminares) do que o enfoque na formação do pós-graduando em disciplinas eletivas dentro ou fora do Programa.

Nessa ótica, a real prioridade está em produzir ciência e participar de eventos científicos, bem como emitir avaliações, pareceres e elaborar artigos, pois é essa a participação que é e será avaliada, julgada e que gera conhecimento publish, uma vez que os critérios de avaliação, capacitação de bolsas, recursos e de inserção do pós-graduando na carreira universitária estão fortemente atrelados à pesquisa. As avaliações externas levam a outro fenômeno desencadeado pelo produtivismo, a intensificação do trabalho do pesquisador que, consequentemente, promove a competitividade e o individualismo, resultantes da disputa por publicações, bolsas e financiamento.

O maior problema atrelado ao produtivismo é que, as publicações postas como quantitativas, são utilizadas como parâmetro de análise de concursos de pesquisadores que se tornarão docentes em IES e progressões de carreiras docentes que ali já trabalham, para obtenção de bolsas e auxílios de pesquisas e, até mesmo, para ter acesso a cargos administrativos nas universidades.

Nesse sentido, é possível refletir se os artigos, capítulos de livros e livros não teriam se tornado uma mercadoria acadêmica que se situa entre o fetichismo e a sobrevivência, tornando-o passível de troca para sobreviver na universidade frente aos ataques das avaliações internas e externas, afinal, hoje - como já dito anteriormente - não se publica para o artigo ser lido, mas sim, para melhorar e complementar o currículo do autor, que vê nele uma oportunidade de acender 
dentro da academia. Para além disso, o desenvolvimento de lógica do produtivismo exacerbado e o conhecimento científico ressignificado em um objeto passível de troca mercantil entre universidades e necessidades do capital, conforma o trabalho dos pós-graduandos à lógica dominante de lucro. Com base nesse fenômeno, Sguissardi e Silva Júnior (2009) afirmam que está na Pós-Graduação a origem de um processo de mercantilização da universidade, pois é nesse espaço que pesquisas alinhadas aos interesses do capital são desenvolvidas, pesquisas essas que, muitas das vezes, são utilizadas para a sua reestruturação em crises cíclicas.

Para Trein e Rodrigues (2011, p. 787), "o capital está empreendendo, de maneira bastante eficiente e eficaz, ao processo de subsunção do valor de uso social do conhecimento à forma-valor, ou seja, a subordinação reificada da ciência à produção capitalista". Ou seja, o fenômeno do produtivismo acadêmico intensifica a participação do capitalismo nas universidades, facilitando a apropriação do conhecimento ali produzido e gerando mais lucros, qualificando as pesquisas dos docentes como mera mercadoria de troca (ibidem).

À vista do que foi explanado até aqui, podemos concluir parcialmente acerca do fenômeno do produtivismo acadêmico, e de suas múltiplas sínteses, que ele se torna mais um, entre tantos, instrumentos de opressão do capital. Um instrumento de articulação para colocar à ciência ao seu dispor. Por meio de sua apropriação do conhecimento científico - no Brasil produzido e financiado respectivamente por universidades e agências de fomento públicas, mas afeitas à lógica do mercado - se propicia redução de custos e do fluxo temporal da produção da riqueza e da acumulação. Com predomínio do desenvolvimento das ciências de aplicação tecnológicas sobre outras ciências; como por exemplo, as ciências humanas.

Nesse sentido, para além de todas as aparências do produtivismo acadêmico, ele enquanto uma política de avaliação adotada pela CAPES, faz-se presente de maneira profícua no desenvolvimento e fundamentação das portarias sequencialmente analisadas, principalmente da portaria 34, afinal, é a partir das avaliações que os programas de pós-graduação são classificados em seus conceitos $(3,4,5,6$ e 7), avaliações essas que são baseadas em critérios produtivistas e conceitos esses que se tornam fator importantíssimo para atribuição de bolsas pela CAPES.

O financiamento da ciência brasileira na contemporaneidade para além de interesses políticos de descrédito das ciências humanas e superqualificação de áreas "estratégicas" para o Governo e o Capital, é baseado em políticas de cerne produtivistas e meritocráticas, punindo pós-graduandos com a falta de bolsas e os culpabilizando por não publicarem como máquinas. Dessa forma, a falta de financiamento advindo pela portaria 34 da CAPES possibilita um projeto de elitização da pós-graduação brasileira, bem como mais um projeto de opressão aos pesquisadores que intentam realizar através da ciência o enfrentamento ao capital e suas mazelas sociais, como elucidamos na seção a seguir.

\section{O NOVO MOdELO DE CONCESSÃo DE bOLSAS E A PORTARIA 34}

No dia 20 de fevereiro de 2020, iniciou-se a divulgação do Novo Modelo de Concessão de Bolsas da CAPES, destinadas aos discentes de mestrado e doutorado dos programas de pós-graduação de IES públicas e privadas no cenário brasileiro. Tendo como justificativa principal a correção de assimetrias presentes no sistema, o novo modelo foi construído com base na valorização dos cursos que apresentam o maior desempenho, fortificando o espírito meritocrático interiorizado em seus processos, tendo como justificativa os pressupostos do produtivismo 
acadêmico presente na produção do conhecimento científico e instituindo um novo padrão de concentração de investimentos. O novo modelo também conta com um dispositivo que beneficia determinadas áreas regionais com menores índices de IDH, além do número de titulações.

Os critérios foram discutidos com a comunidade acadêmica e foi estabelecido que a concessão de bolsas se daria com base numa projeção que relaciona: a) nota dos cursos de acordo com a avaliação quadrienal de pós-graduação da Capes - cursos com notas maiores obteriam mais bolsas em detrimento dos cursos com notas mais baixas; b) nível do curso - o curso de doutorado ganha mais bolsas que o mestrado, além de que a área do curso (exatas, humanas e biológicas) também possui notas diferentes; c) IDH do município - quanto menor se apresenta, maior a quantidade de ter bolsa; d) Tempo médio de titulação - cursos que titulam mais tendem a ganhar mais bolsas em relação aos que titulam menos.

As regras estabelecidas pelas portarias 18, 20 e 21 alicerça a normativa de concessão de bolsas e lança mão de critérios e limites de concessão para os editais dos seguintes programas: Programa de Demanda Social (DS); Programa de Excelência Acadêmica (Proex); Programa de Suporte à Pós-Graduação de Instituições de Ensino Particulares (Prosup) e Programa de Suporte à Pós-Graduação de Instituições Comunitárias de Ensino Superior (Prosuc).

As portarias determinam e reforçam, ao longo de suas regulamentações, um teto de cortes e ganhos que não poderia ser menor ou maior que 10\%. A CAPES abre exceção destas regras apenas para os cursos de excelência (Proaex), ponderando que o ganho de bolsas para estas categorias poderia se estender em até 30\%.

Dentro do modo operatório das portarias, constata-se que, a partir do momento em que as projeções fossem feitas, ficariam discriminadas as cotas que de fato pertenciam ao curso e as cotas excedentes. Logo, à medida que os pós-graduandos comtemplados com bolsas/cotas excedentes concluíssem a pesquisa, as cotas não continuam no programa de pós-graduação, voltando a pertencer à sua instituição concessora, isto é, a CAPES que, ao final do processo, daria encaminhamentos para onde ela será redistribuída. Esse movimento, entretanto, obedeceria a limitação dos $10 \%$.

Como consequência direta, tem-se, aliás, o esgotamento da autonomia na concessão de bolsas oriundas de editais próprios das Pró-Reitorias de Pós-Graduação, centralizando essa responsabilidade apenas para a CAPES. Em longo prazo, e juntamente com os cortes sistemáticos de investimentos em ciência e tecnologia no país, as portarias são colocadas como uma legitimidade da normalização da pós-graduação sem bolsas.

O conjunto de portarias que organiza o novo modelo sofre críticas em relação a lógica que se propõe de se desresponsabilizar de cursos com menores notas ao invés de propor insumos que promovam o desenvolvimento dos mesmos.

A discussão acerca da elaboração de um novo modelo de concessão já permeava como um dos principais assuntos no contexto de produção acadêmica e àqueles vinculados a ela. Apesar das críticas, nota-se que a elaboração das primeiras normatizações foi intercaladaa com momentos de conversação juntamente com a comunidade acadêmica, a exemplo das reuniões com o Fórum Nacional de Pró-Reitores de Pesquisa e Pós-Graduação (FOPROP), a ANDIFES, representantes do SBPC e o Conselho de Coordenadores das 49 áreas de conhecimento da Capes desde o ano de 2019. Cabe frisar, portanto, que a presença de entidades representantes da 
comunidade acadêmica nas primeiras portarias conseguiram amortizar, em partes, efeitos ainda mais nefastos.

Entretanto, tais efeitos foram retomados com a portaria 34, ora realizados sem participação política da comunidade acadêmica, desenvolvendo uma inigualável força no desmonte. A nova portaria foi assinada no dia 9 de março de 2020 (e efetivamente publicada em 18 de março de 2020), seguindo orientações do Ministério da Educação (MEC). Nesse momento, os Programas de Pós-graduação já estavam cientes das cotas disponíveis de acordo com os critérios anteriores, assim já haviam feito as seleções, informado aos alunos sobre a concessão e, tal como relatado em diversos casos, muitos deles já haviam assinado termos de consentimento.

Consoante orientação central do Ministério da Educação e tendo em vista o resultado de reunião ocorrida hoje, bem como a alta receptividade do modelo de redistribuição de bolsas determinada no final de fevereiro deste ano, identificou-se a conveniência de ampliar a velocidade de sua implantação, de modo a potencializar o caráter meritocrático que o notabiliza. (COORDENAÇÃO DE APERFEIÇOAMENTO DE PESSOAL DE NÍVEL SUPERIOR, Portaria 34, de 9 de março de 2020)

Dentre suas principais características, a portaria é caracterizada pelo ato da CAPES de voltar atrás da decisão acerca dos pisos e tetos para concessão de bolsas. Ela reconfigura as regras anteriormente fixadas em fevereiro de 2020 e amplia a autorização de diminuição de bolsas de acordo com a nota de cada curso de Pós-Graduação.

Art. $8^{\circ}$ Fica determinada a revisão dos pisos e dos tetos da redistribuição de bolsas definida pelas Portarias $n^{\circ} 18, n^{\circ} 20$ e $n^{\circ} 21$, de fevereiro de 2020, de modo a conferir maior concretude à avaliação da pós-graduação e maior prioridade aos cursos mais bem avaliados, cujo resultado final deverá obedecer aos seguintes limites:

I - diminuição não superior a 50\% (cinquenta por cento), para cursos cujas duas últimas notas forem iguais a 3 (três), vedado qualquer acréscimo;

II - diminuição não superior a $45 \%$ (quarenta e cinco por cento), para cursos cuja nota atual for igual a 3 , vedado qualquer acréscimo;

III - diminuição não superior a $40 \%$ (quarenta por cento) ou acréscimo limitado a $10 \%$ (dez por cento), para cursos cuja nota atual for igual a 4 ;

IV - diminuição não superior 35\% (trinta e cinco por cento) ou acréscimo limitado a $30 \%$ (trinta por cento), para cursos cuja nota atual for igual a 5; ou

$\mathrm{V}$ - diminuição ou acréscimo a 10\% (dez por cento), para cursos de nota $\mathrm{A}$ ou de nota 3 ainda não submetidos a processo de avaliação de permanência;

VI - diminuição superior a 30\% (trinta por cento) ou acréscimo a 70\% (setenta por cento), para cursos cuja nota atual for igual a 6 ; ou

VII - diminuição não superior $20 \%$ (vinte por cento), para cursos cuja nota atual for igual a 7, sem limitação de teto. (COORDENAÇÃO DE APERFEIÇOAMENTO DE PESSOAL DE NÍVEL SUPERIOR, Portaria 34, de 9 de março de 2020)

Em suma, esta medida é interpretada como um dispositivo que desloca os efeitos danosos em longo prazo para o curto prazo. Ela transforma de forma abrupta o processo de transição do novo modelo de concessão de bolsas e fornece autonomia ainda maior para CAPES fazer o que almejar. A portaria destaca-se pela interferência no planejamento, ora em andamento, das pesquisas científicas, assim como causou múltiplos constrangimentos a estudantes dos programas de pós-graduação que já tinham o dado como certo o recebimento da bolsa.

Para melhor elucidação, colocamos em evidência o caso da UFPR. De acordo com o documento assinado em repúdio à portaria 34 , estima-se que as primeiras portarias resultaram na 
perda de 105 bolsas de mestrado e 95 de doutorado. Em função das novas mudanças apresentadas pela portaria 34, a instituição sofreu uma segunda perda, totalizada em 597 bolsas (294 bolsas de mestrado e 303 bolsas de doutorado). O valor representou, respectivamente, uma perda de $27 \%$ e $24 \%$ do montante de bolsas.

Apresentados os principais elementos, torna-se possível traçar algumas linhas de análise em relação a portaria acerca do que ela se propõe a implantar e avançar em lógicas por vezes já existentes na organização de trabalho docentes e pós-graduandos. É preciso localizar a portaria, ademais, enquanto um processo que está sendo sistematicamente aprimorado ao longo dos anos. O Estado é um elemento primordial nesse processo em decorrência do seu papel de regulador-avaliador, uma vez que, a partir de sua fundamentação em de princípios meritocráticos, ele acaba por deslocar a responsabilidade estritamente ao caráter individual.

Druck (1996, p. 24) reforça que a mentalidade global "oculta às responsabilidades sociais e políticas e acaba por naturalizar os fatos sociais" e isso não é diferente quanto aos encaminhamentos dados ao cenário do financiamento da produção cientifica. O pesquisador, coadunando com a lógica que se instaura, deixa de ser responsabilidade do Estado e passa a ser gestor de si, numa analogia ao homem empresarial, o que compactua cada vez mais com o estabelecimento de corpos flexíveis e individualizados que se adequam a esse modo de gestão, e também fortifica a questão do desamparo na contemporaneidade. Existe, em curso, a fortificação de exemplos de criação de rankings entre mestrandos e doutorandos, com base no número de publicações, para concessão de bolsas e visibilidade de docentes. O trabalho do pesquisador é absorvido pela lógica da flexibilização e do produtivismo, tentando adaptar-se às múltiplas demandas da escrita acadêmica, prazos, disciplinas, publicações.

Transfere-se também a responsabilidade para as universidades e os respectivos programas de pós-graduação, sendo estes últimos frequentemente encurralados com os déficits, o que aumenta o sentimento de inexorabilidade e, como consequência, acarreta a tomadas de decisões voltadas para a captação de recursos próprios a partir de parcerias com a iniciativa privada, fortificando a lógica privatista e a redução da autonomia universitária.

A primeira característica que se destaca ao analisar a portaria, portanto, centra-se em uma normatização de desigualdades quanto à distribuição de recursos, isto é, logo normaliza o fato de que diversos estudantes de pós-graduação continuem a desenvolver suas pesquisas sem a devida contrapartida remuneratória. Tal fato fortifica a existência de um sistema pautado pela desigualdade, onde a meritocracia é institucionalizada para atuar como um dispositivo de validação do subfinanciamento. Ao aumentar a discriminação entre pós-graduandos, docentes, programas de pós-graduação e universidades, intensifica-se as formas de sociabilidade mais competitivas, responsabilizando os indivíduos, o que por sua vez, cria uma maior adesão para que estes se tornem cúmplices de sua própria servidão.

A corrida pela adequação aos parâmetros suficientemente bons para alcançar um número satisfatório de bolsas intensifica a cobrança por produtividade. Isso desencadeia um conjunto de fatores psicossociais, assim como interfere no processo de formação dos pós-graduandos, visto que ela se transfigura de um processo de apropriação do conhecimento para uma série de experiências fragmentadas que, possuem como finalidade central, a acumulação de quantitativos. Diante desse cenário, o estudante pode começar a apresentar uma perda da narrativa integralizada em relação à sua atividade. 
O segundo ponto a ser considerado é a designação dada ao que vem a ser o direito à educação. Durante o processo do Ministério Público Federal, a portaria 34 foi acusada de prejudicar a vida de vários estudantes e que, consequentemente, a concretização de suas ações levaria a subtração dos direitos à educação de uma parcela de pós-graduandos que tiveram a bolsa cortada. Em contraposição, em umas das laudas de contra argumentação, a Advocacia Geral da União, em defesa da CAPES, alegou que não houve subtração destes direitos.

\begin{abstract}
Isso porque a ninguém está sendo denegado o acesso à educação. O que ocorreu, segundo a inicial e que se concede apenas ad argumentandum tantum, seria o cancelamento de determinadas bolsas de estudo para alguns pesquisadores ou centros de educação superior. Ora, ainda que fosse essa a realidade posta (que não é, conforme será detidamente explanado nesta defesa), aluno algum foi impedido de se matricular em pós-graduação, ou tampouco se proibiu oferta de curso semelhante. Sobre estes fatos não há discussão: a Capes não determinou revogação ou impedimento de matrículas, nem o fechamento de cursos de pós-graduação. (ADVOCACIA-GERAL DA UNIÃO, p.4, grifos no original).
\end{abstract}

A argumentação reforça o fenômeno do subfinanciamento como normal, bem como simplifica o direito a educação ao quantitativo de matrículas, eximindo-se de todas as condições materiais e relacionais essenciais para a efetivação da formação humana e socialmente referenciada. Questiona-se, nesse sentido, até que ponto a política dá conta de contradições presentes no trabalho de pós-graduandos no que diz respeito às condições objetivas de vida no seu âmbito social, familiar e financeiro do sujeito. Não bastasse a desigualdade interiorizada no país, fortifica-se o avanço de uma desigualdade no interior do funcionamento da produção científica.

Há de se pensar, ademais, as formas de violência que são produzidas em decorrência da institucionalização de tais ações. Existe violência implícita na forma como o sistema capitalista se refere ao trabalho desenvolvido pelo pós-graduando. Ela diz respeito a recusa da constatação do desenvolvimento da pesquisa enquanto um trabalho e ao fato de que a bolsa é um modo de subsistência e retribuição simbólica valorativa ao trabalho realizado.

Destacamos ainda, um processo de aprofundamento da hierarquização dos saberes, nos quais as mais afeitas ao papel mercantil da ciência são as privilegiadas. O ministro da educação divulgou, por meio das redes sociais, o deslocamento de bolsas do colégio humanidades para as ciências da vida e exatas. Como consequências do processo de redistribuição das bolsas empréstimo, 75.2\% das bolsas ficarão concentradas nas duas últimas áreas citadas. As exatas disporão de 32,243 (38,1\%) das bolsas; a área de ciências da vida contarão com 31.476 (37,1\%), enquanto que as humanidades terão 21.067 (24,8\%).

Ao mesmo tempo que se aprofundam as desigualdades e se fortalece o domínio das ciências aplicadas, se forja uma representação das ciências humanas como portadoras de discursos políticos, ideologicamente acusados de doutrinários, sendo um dos alvos dessa área um dos intelectuais mais reconhecidos da história da educação brasileira: Paulo Freire.

Nessa ótica, as portarias lançadas pela CAPES, sobretudo a Portaria 34, caracterizam-se e se configuram enquanto valiosos instrumentos da operacionalização da exacerbação da forma política do Estado, cuja matriz é a forma-valor ou forma-mercadoria (MASCARO, 2013). O que implica em elitização, dominação e produção da ciência brasileira divorciada progressivamente da função social que seria permitida dentro do quadro circunscrito do Estado funcional capitalista, que no atual quadro do Governo Federal, tende a silenciar cada vez mais o que não seja 
rentável. As portarias fazem parte de um grande projeto de reestruturação do Estado nos moldes do ultra liberalismo, proposto pelo presidente Jair Bolsonaro e implementado por seus ministros, desde Paulo Guedes, até, em nosso caso particular, da Educação, pelo Ministro Abraham Weintraub. O que é seguido pelos encaminhamentos do Presidente da CAPES, Benedito Aguiar.

Uma vez expostas algumas análises das Portarias lançadas pela CAPES aqui referenciadas, analisamos, na próxima seção, os resultados dos questionários aplicados aos alunos dos 11 Programas de Pós-Graduação da UFPR, no intuito de explicitar, num plano concreto, os impactos psicossociais que os cortes acarretaram na vida desses pesquisadores.

\section{ANÁlise do QUESTIONÁRIO E SEUS IMPACTOS PSICOSSOCIAIS E POLÍTICOS}

Como já explicitado na seção acerca da metodologia e do método de análise, aplicamos um questionário eletrônico composto por perguntas abertas e fechadas para pesquisadores de 11 Programas de Pós-Graduação da UFPR de três grandes áreas do conhecimento: Ciências Biológicas, Ciências Exatas e Ciências Humanas.

A partir do envio do link do questionário via e-mail para as secretarias dos programas selecionadas, o mesmo permaneceu disponível por 15 dias consecutivos. O envio do link ocorreu no dia 20 de abril de 2020 e permaneceu aberto para respostas até o dia 04 de maio de 2020. Foram obtidas 72 respostas, expostas na Tabela abaixo:

\begin{tabular}{|l|l|l|l|}
\hline ÁREA DO CONHECIMENTO & MESTRADO & DOUTORADO & TOTAL \\
\hline CIÊNCIAS BIOLÓGICAS & 03 & 18 & 21 \\
\hline CIÊNCIAS EXATAS & 04 & 08 & 12 \\
\hline CIÊNCIAS HUMANAS & 18 & 21 & 39 \\
\hline
\end{tabular}

A pesquisa dispõe de uma amostra na qual 65,3\% dos participantes são oriundos do curso de doutorado, enquanto que 34,7\% pertencem ao curso de mestrado. Em relação as áreas de conhecimento: 29,2\% são pertencentes à área de ciências biológicas; 16,7\% pertencem ao colégio de ciências exatas e 54,2\% são pertencentes à área de ciências humanas. No que diz respeito às notas dos programas: $8,3 \%$ dos participantes estão em programas de conceito $4,66,7 \%$ conceito $5,22,22 \%$ conceito 6 e $2,8 \%$ conceito 7 . Ao serem questionados sobre o ano de ingresso no programa foi constatado que $11,1 \%$ dos participantes teve o ingresso em $2017 ; 28 \%$ em 2018; 20,8\% em 2019 e $31,9 \%$ em 2020. Diante do posto, a pesquisa comtemplou uma amostra diversificada de sujeitos que se encontram na pós-graduação, mas que compartilham situações e afetos semelhantes em decorrência do trabalho que desenvolvem.

A atividade de estudo aqui será tratada como similar à atividade do trabalho, em contraposição às múltiplas facetas do senso comum que tentam reduzi-lo a uma simples ação de aprendizado (SILVA, 2020). Compreendemos o trabalho como elemento fundamental de emancipação do sujeito (DEJOURS, 2012), circulação de afetos, formação, inventividade humana e ação política. E ressaltamos que as transformações do trabalho do pesquisador seguem as metamorfoses ocorridas no mundo do trabalho nos últimos anos.

Seguindo a descrição dos discentes, $64(88,9 \%)$ dos participantes relatam serem financiados com bolsas de pesquisa, enquanto que $8(11,1 \%)$ não são comtemplados com a bolsa. Por outro lado, ao serem perguntados sobre avaliação do quantitativo de bolsas referente ao programa de pós-graduação no qual se encontram 42 dos 72 entrevistados $(58,3 \%)$ julgam o número de bolsas insuficiente, bem como 3 dos participantes (4,2\%) consideram o número de bolsas ruim. 
Concomitantemente, $40(55,6 \%)$ dos participantes alertam ter sofrido um alto corte do número de bolsas nos últimos anos; 23 participantes $(31,9 \%)$ estimam que o programa de pós-graduação no qual se encontram sofreu redução média do número de bolsas e 7 participantes $(9,7 \%)$ consideram que tiveram uma redução baixa, em contraposição, apenas 2 participantes $(2,8)$ analisam que não houve cortes.

Quando perguntados sobre a ocorrência de corte de bolsas após a defesa de atuais bolsistas e impedimento de sua transferência para estudantes da lista de espera, $12(16,7 \%)$ dos participantes alegam que isso sempre ocorre com grande frequência; $39(54,2 \%)$ relatam que acontece às vezes; $17(23,6)$ dizem que isso ocorre com pouca frequência e $4(5,6 \%)$ alegam que não houve cortes. Sobre cortes de bolsas já atribuídas no sistema CAPES, 29 (40,3\%) dos participantes alegam a não incidência de cortes após a atribuição; $16(22,2)$ disseram que o corte acontece com frequência baixa; $17(23,6 \%)$ relatam que os cortes acontecem em frequência média e $10 \%$ alegam que acontecem com alta frequência. Quanto ao impacto dos cortes no funcionamento dos programas de pós-graduação, 58 participantes $(80,6 \%)$ avalia a situação como extremamente preocupante e $(11,1 \%)$ considera muito preocupante, totalizando $91,7 \%$.

Simultaneamente, os dados apontam para um acúmulo de pressão por produtividade. De acordo com as respostas dos participantes, $12(16,7 \%)$ assinalam ser excessivamente pressionados em relação aos estudos para as disciplinas, pesquisa, exigências de produção e publicação; $31(43,1 \%)$ se sentem muito pressionados; $20(27,8 \%)$ se sentem pressionados; $8(11,1 \%)$ disseram que as demandas são adequadas e $1(1,4 \%)$ não se sente pressionado.

Ao serem questionados sobre o conhecimento do conteúdo da portaria 34, 41 (56,9\%) dos participantes declaram ter ciência sobre ela; 24 participantes (33,3\%) declaram que souberam da portaria, porém não em detalhes e 7 participantes $(9,7 \%)$ declaram não saber da portaria.

Na seguinte frase "Com o corte de bolsas realizados através da Portaria 34 da CAPES, a pós-graduação brasileira irá sofrer uma reestruturação. O seu acesso ficará mais restrito às classes mais elitizadas. E é possível que mesmo os programas com notas máximas (6 ou 7), independentemente da área do conhecimento, venham a sofrer diminuição e/ou cortes de bolsas", 42 participantes $(58,3 \%)$ concordam plenamente com a afirmação; 15 (20,8\%) concordam; $4(5,6 \%)$ concordam parcialmente; $2(2,8 \%)$ discordam parcialmente; $1(1,4 \%)$ discordam e $8(11,1 \%)$ discordam totalmente. Isso significa que mais de $80 \%$ dos participantes concordam que em algum grau a medida pode afetar a permanência de discentes na pós-graduação.

Por fim, pedimos aos participantes que indicassem o grau de impacto ( 0 a 10$)$ do corte de bolsas de acordo com as seguintes categorias: 


\section{Clafissicação média das respostas}

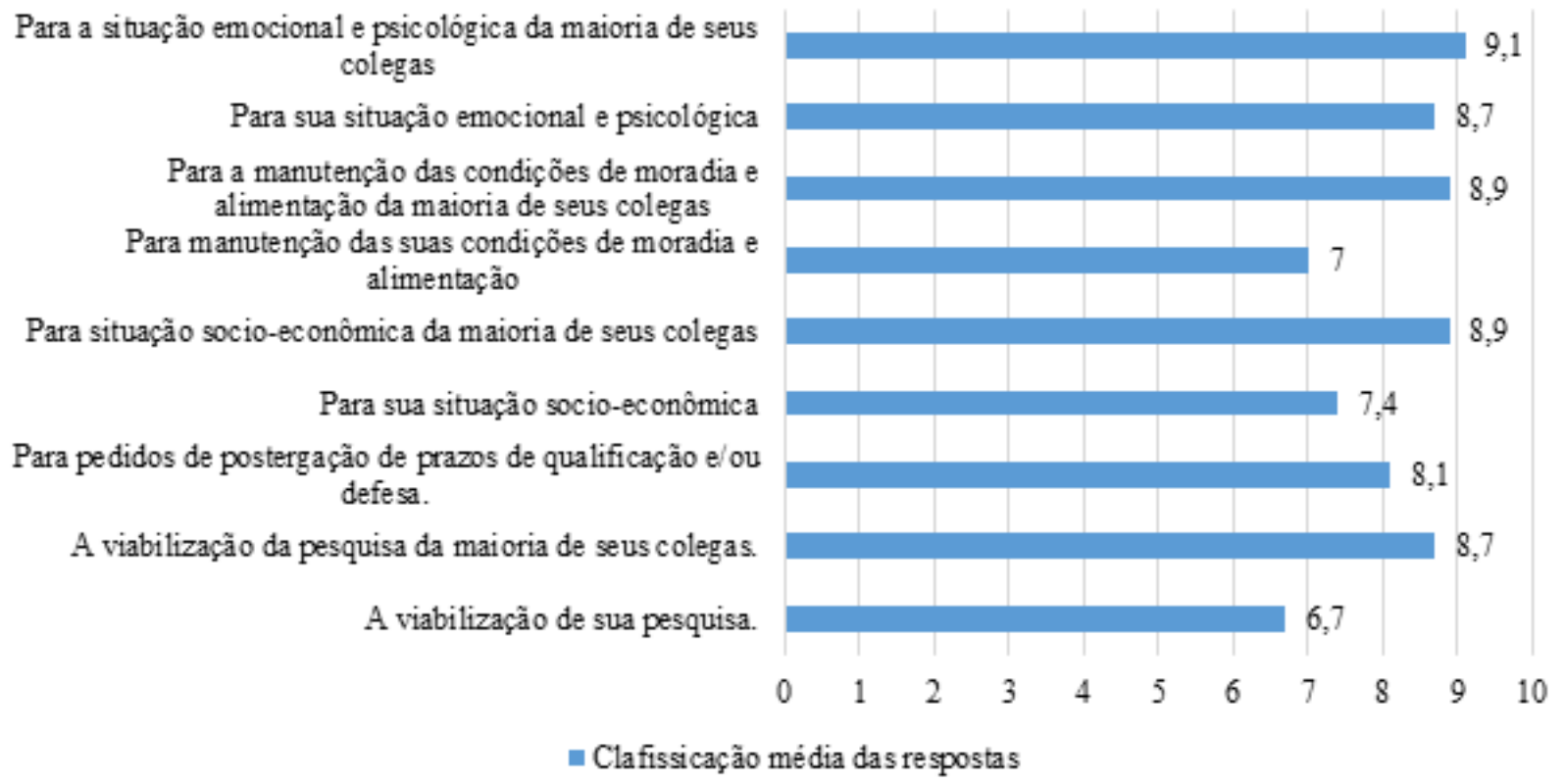

Gráfico classificatório da média das respostas. Gráfico criado pelos autores.

Os cortes de bolsas são um dos elementos desencadeadores de sofrimento mais recorrentes dos pós-graduandos, afetam sobremaneira seus modos de organização de trabalho, quando não abortam projetos acadêmicos e profissionais. Como veremos, a questão econômica implica também em efeitos subjetivos nefastos, alguns deles já pré-indicados no quadro acima.

Considera-se que a incerteza vivenciada a partir do subfinanciamento da ciência e tecnologia no Brasil, bem como a escassez de recursos materiais que possibilitam a operacionalização do trabalho têm atuado fortemente como um dispositivo de desestabilização. Cabe ressaltar que os modos de experimentação da atividade do trabalho interferem em todos os âmbitos do cotidiano - lazer, vida familiar, relacionamentos afetivos, ética, moral, educação, etc - e atinge, em cheio, as subjetividades.

As percepções dos pós-graduandos, aqui expressas, serviram como balizadoras para a compreensão acerca do impacto da insegurança na vida e nos modos de experimentação do trabalho. Considera-se que as formas de sofrimento narrado neste presente trabalho não devam ser interpretadas de forma individualizada, cujos meios de enfrentamento redundem em formas individualizantes de resistência, mas procura-se localizá-lo enquanto um fenômeno coletivo, derivado das sínteses presentes na crise da sociedade capitalista e de suas produções pelo produzir como um fim em si mesmo. Expressa por um de nossos respondentes: "Nosso programa é bastante conceituado, mas a pressão por publicações é alta".

Logo, o trabalho do pesquisador é recheado de pressões em decorrência da produtividade, entretanto as contrapartidas dos recursos materiais e simbólicos que alicerçam o sentido do trabalho, muitas vezes, não acompanham a intensidade de tais imperativos.

Os pós-graduandos estão situados no meio de um jogo de forças, de acordos e desacordos que impactam diretamente as suas vidas e os modos de se relacionar com o seu trabalho. Entretanto, é certo dizer que eles não possuem participação concreta sobre estas decisões, desenvolvendo formas limitantes de realização. Essa imprevisibilidade e a falta de domínio acerca de 
suas vidas gera o sentimento de desamparo, o medo constante pela perda do lugar, assim como o medo sobre o futuro de si e pelo futuro dos outros colegas.

"Agora, tenho (bolsa). Mas apenas depois da devolução de bolsas recolhidas por "erro" da CAPES. Passei em primeiro lugar no processo seletivo e quando descobri que todas as bolsas tinham sido recolhidas, foi devastador. Agora, mesmo com o retorno da bolsa, o medo de perdê-la é constante".

Destacamos, com base em Dejours (2004), que o trabalho é muito mais do que produzir, e seu sentido derivado de sua eficácia enquanto atividade mediadora entre o desejo e o campo social. Mais do que uma retribuição financeira, ele serve como retribuição simbólica, na qual os esforços dedicados, e os sofrimentos inevitáveis de que ele é portador no enfrentamento do indivíduo às adversidades do real, são repatriados à subjetividade enquanto gratificação, desde que preservadas a autonomia, cooperação e solidariedade. $\mathrm{O}$ trabalho, que pode ser fonte de adoecimento, quando impedido, ou forjado sem garantir autonomia, ou avaliado por formas discrepantes ao seu valor ético e político (DEJOURS, 2008), pode, por outro lado, ser elemento constitutivo da identidade individual e social, e, portanto, atividade socialmente relevante e reconhecida: "o trabalho é, certamente, o mediador privilegiado e insubstituivel entre o inconsciente e o campo social” (DEJOURS, 2004, p.168). Mas o afastamento da política do bem comum, da produção do conhecimento e da formação humana, em prol dos ideais mercantis e da rentabilidade a todo custo, ao invés de propiciar o desejado campo social das narrativas e projetos estruturados e respaldados, desloca o ser social para o assombroso mundo das incertezas:

"O pior momento foram as semanas de incerteza quanto as bolsas. É um sentimento terrivel, de desvalorização e de abandono".

Os efeitos econômicos podem ser muitas vezes destacados, dada sua imediaticidade:

"Devido ao corte ser inesperado, todos fomos pegos de surpresa, sem saber como iríamos pagar o aluguel no próximo mês. Devido a conjuntura atual do mundo, fica muito dificil de arranjar um emprego ou até mesmo freelancer para pagar as contas".

Mas mais do que isso, há os efeitos deletérios que acusam o rompimento com os valores democráticos e da justiça que são a base do pacto social. Os valores civilizatórios são substituídos por um processo de banalização da injustiça social, tal como denomina Dejours (2006), ao criticar os modos de gestão pautados pelo medo, ameaça e indução do individualismo e competitividade.

"Considero a medida autoritária e injusta. Muitas pessoas já haviam se organizado para começar sua pós com bolsa e tiveram problemas nesse sentido".

O trabalho, antes reconhecido, passa por um processo de desvalidação social, o que pode acarretar numa desvalorização de si, da própria identidade, como se o sujeito perdesse a autoria dessa sua atividade social fundamental, ou ainda, seu projeto (que obviamente não se limita ao "projeto de pesquisa", pois este se vincula ao "projeto de existência").

"Como consequência dessa instabilidade, não planejo continuar a pesquisa no doutorado."

"Fui aprovado no processo seletivo para o Doutorado, já tendo em mãos um projeto que foi aprovado e financiado em edital da FA, de minha autoria. Uma semana antes do período de matrícula soube que não haveria mais a bolsa. Como consequência não há possibilidade de eu realizar o projeto, nem o doutorado" 
Traçando uma linha de raciocínio da representação da bolsa na vida de um pós-graduando, pode-se concluir que ela dispõe de dois eixos norteadores: um eixo representado pela condição material e o eixo simbólico. A primeira refere-se a contrapartida monetária como uma forma de suporte material para a realização das tarefas vinculadas a pesquisa, sendo também bastante enfatizada como um salário que é fruto da trajetória formativa do pesquisador, de utilidade técnica, social e econômica que discorre sobre o trabalho realizado no seu aproveitamento geral, sua valoração, sua serventia. Por outro lado, tal reconhecimento proporcionado pela bolsa também impacta na própria identidade do pesquisador.

A bolsa nesse sentido, é uma forma de retribuição simbólica de outrem para que o sujeito veja sentido em suas ações, sua trajetória e nos seus modos de realização do trabalho (LIMA, 2013). É uma forma de validação e legitimação das ações de um sujeito, de reconhecimento. Essa validação possibilita dar sentido à vivência do sofrimento, e constatar que experiências de constrangimento não são em vão, mediante encaminhamentos significativos para que esse sofrimento tenha sido elaborado de forma a contribuir para a produção de sentido e sublimação. Quando vigora a mediação subjetividade-sociabilidade por meio do trabalho, este "toma a forma específica da sublimação"; do contrário, se produzem situações "anti-sublimatórias" que "operam contra a construção da identidade" (DEJOURS, 2004, p.169). A falta do reconhecimento objetivada no corte de bolsa desencadeia um conjunto de dissonâncias entre um projeto de vida que o pós-graduando criou e a realidade que ele se encontra.

"Possuo bolsa desde a entrada no mestrado. Encaro ela como a remuneração por um trabalho (de pesquisa). Ao mesmo tempo, a bolsa foi muito importante para eu de fato realizar o mestrado-pois envolveu uma mudança de cidade, arrumar lugar para morar etc".

"As bolsas devem ser tratadas como salário e fundamentais para a manutenção do pesquisador e do cientista. A expansão desenfreada dos programas de pós dispersou recursos em centros de excelência e também coibiu reajustes anuais de bolsas, o que permitiria a vinda de pesquisadores para centros maiores, dado o valor menor da bolsa e o alto custo de vida. No entanto, bolsa não se trata de auxílio social, mas um retorno de um trabalho de alta qualidade e que merece respeito e seriedade".

O efeito econômico e simbólico, concreto e subjetivo, real e simbólico, acarreta também efeitos nocivos à saúde, tendo sido relatados aspectos como sentimento de impotência, falha, incompetência, medo, ansiedade, ou ainda, sintomas depressivos e até mesmo um caso de estudante que se referiu à ideação suicida, dada a repercussão intensa que lhe abateu a situação de aborto de um projeto, desesperança e medo.

"Extremamente preocupante, uma vez que são cortadas, mais uma vez, bolsas de pesquisa em momentos decisivos para o país. Minha pesquisa se relaciona aos efeitos psicológicos da ansiedade em isolamento, e por falta de financiamento, corro o risco de precisar abandoná-la a qualquer momento. Infelizmente no Brasil, pesquisa é vista como um passatempo, e não como uma grande contribuição ao desenvolvimento do país".

"Por não residir em Curitiba com meus pais, a falta da bolsa e de fonte de renda na pandemia fez com que minha única opção seja depender financeiramente de meus pais novamente, o que gera sentimentos de falha e impotência. Mesmo estando habilitada para receber bolsa, o beneficio foi removido".

"Sinto um fracassado por faltar dinheiro. É uma situação desestimulante, perder a moradia, ser despejado, passar necessidade de dinheiro e ter que pedir empréstimo negativado. Sem condições de conclusão de um trabalho e a desistência de colega participante não foi renovada a bolsa". 
"Estou pensando seriamente em desistir do mestrado por não conseguir me manter no mesmo financeiramente e não dispor da possibilidade de trabalhar".

"O corte fez as despesas não serem honradas nos prazos combinados pusemos dinheiro de empréstimos pessoais para dar continuidade".

Para muitos, a bolsa também representa, para além da garantia do andamento da pesquisa com dedicação exclusiva, a garantia de necessidades básicas, tendo em vista que muitos pós-graduandos se deslocam de suas cidades e arcam com diversos custos extras por conta das mudanças. A mudança do perfil de discentes da pós-graduação e a expansão do acesso dos cursos de pós-graduação, entre seus avanços e contradições, também traz novos contornos e ampliação de necessidades relacionadas ao suporte social a esse novo perfil. A bolsa passa a ser representada como recurso de permanência, de modo a suprir condições objetivas de vida.

A ampliação de cortes, vinculadas aos aspectos meritocráticos e produtivistas, são interpretadas como um recuo no que tange o combate à elitização nos meios de pós-graduação.

"Será um retrocesso gigantesco para a ciência. Perderemos a possibilidade de encontrar grandes cientistas entre as camadas mais pobres da população. Com a volta da elitização do ensino as diferenças sociais se acentuarão ainda mais. Com menor mão de obra especializada, seremos cada vez mais dependentes do mercado externo, ou seja, nunca deixaremos de ser uma colônia".

Relatos de jovens que, ao contrário do que se apregoa por vezes nos discursos dominantes, seriam alienados ou individualistas, revelam, outrossim, consciência política e indignação com a banalização da injustiça social e preocupação com o coletivo e com as desigualdades sociais: "As consequências são muitas. Sociais porque menos pessoas das classes mais pobres poderão ter acesso a qualificação profissional e assim teriam pior remuneração. Consequências culturais também porque pessoas pobres vão ter menos acesso à informação, conhecimento e especialização. E por fim terão consequências politicas e econômicas, porque o Brasil continuará mantendo um quadro histórico de deficiência de mão de obra altamente qualificada, dependendo de importação de serviços e produtos especialmente".

"Isso fará com as classes que já têm privilégio no acesso à educação mantenham esse privilégio, que acaba se estendendo para a carreira, poder aquisitivo e assim por diante. É triste que o governo proponha a perpetuação desse sistema".

"Somos todos adultos, com responsabilidades, com familia, com contas pra pagar. Quem não tem estabilidade financeira de berço vê na educação uma forma de ascensão. Mas de que jeito estudar/pesquisar/trabalhar sem bolsa? Como sobreviver?"

A banalização da injustiça social, como aponta Dejours (1999, p.119), "começa pela manipulação política de ameaça de precarização e exclusão social". Exclusão que se alia à hierarquização dos saberes, também percebida pelos estudantes e apontada de forma crítica:

"A portaria tem um impacto extremamente negativo na alocação de bolsas, especialmente para programas com notas menores. A única maneira de aumentar a qualidade do programa é com o ingresso de novos alunos para a manutenção e aumento no número de publicações do dito programa, com estes cortes programas com notas baixas não terão a mesma chance de melhorarem e poderão ser fechados no futuro". 
Torna-se importante ressaltar que, dentro das práticas de ensino pautadas no mérito e individualização, existe uma tendência de gerar conflitos e competição entre os estudantes. Enunciações e práticas que atingem a dimensão cooperativa e coletiva, fundamental ao reconhecimento e ao trabalho de qualidade e sublimatório, uma vez que "a sublimação só é possível quando estão reunidas condições éticas e sociais precisas" (DEJOURS, 2004, p.170). Na ausência dessas, há a distinção discriminadora entre os que conseguem gerir os imperativos de produção e os que não conseguem, ou ainda, dos cursos que conseguem se manter dentro dos padrões ditos de "excelência" do produtivismo acadêmico, e dos que não conseguem.

A contrapartida monetária unicamente para aqueles que possuem notas mais altas é uma forma de cristalizar o imaginário do aluno que dá conta das questões da universidade e da vida pessoal. Isso é relatado no estudo de Fajoses (2019) quando os estudantes descrevem a "fulana" - uma pessoa, uma idealização projetada em um colega que eles imaginam que dá conta de todas as demandas possíveis e impossíveis. No final dos grupos focais, os alunos admitem que a "fulana" talvez não exista, mas que ainda sim os alunos continuam se comparando com ela.

É a partir deste exemplo que sinalizamos a dinâmica que se desdobra da discriminação dos estudantes. Ao final do processo, é notável que todos sofrem, mas o peso do estigma que os estudantes carregam é forte demais para se desvencilhar. Diante disso, estudantes sofrentes com notas altas penam para continuar no pedestal ilusório, enquanto que estudantes sofrentes com notas menores penam para alcançar o pedestal. O looping (MANCEBO, 2009) da lógica do medo está instaurado, juntamente com a sociabilidade competitiva. Como adiantávamos, por consequência disso, há um conjunto de dissonâncias entre a expectativa e a realidade apresentada aos estudantes, acrescida de uma série de dificultadores para a realização do trabalho. Isso produz uma série de consequências emocionais e psicológicas, produtos de uma sociabilidade devastadora:

"Me sinto desmotivada a continuar a pós graduação e sinto uma profunda tristeza em pensar nas consequências que a falta de estudo irá causar ao país".

"Eu preciso muito da bolsa no mestrado para continuar estudando neste momento sinto-me muito mal e deprimida com toda esta situação".

"O aspecto psicológico é fundamental. Com o corte e o insucesso de obter um emprego formal (devido ao Covid-19) entrei em estado de depressão. Sem renda, sem plano de saúde, estou aguardando consulta com psiquiatra para tentar superar esta situação".

"Mesmo que esta portaria seja revogada ela já teve um impacto profundo nos pós-graduandos. Eu, e vários colegas, estamos desanimados, sofrendo com uma estafa emocional profunda. Sofrer essas retaliações constantes só nos deixa mais inseguros sobre o quanto vale a pena a carreira científica no Brasil".

"Me faz ter pensamentos suicidas. Não há esperanças para o futuro".

Os processos de saúde-adoecimento dos pós-graduandos, como apontamos, estão ancorados nas formas de vida contemporâneas; e seus sofrimentos, estresse e adoecimentos, são engendrados por situações institucionais, sociais e psicossociais nas quais, como argumenta Dejours (2004, p. 170, 1999), há uma ruptura com "condições éticas e sociais precisas"; tal ruptura fragi- 
liza o reconhecimento, a cooperatividade e o fazer coletivo, elementos fundamentais à produção do conhecimento científico e à manutenção da saúde e da esperança.

Segundo Canguilhem (2002, p. 151) "o que caracteriza a saúde é a capacidade de ultrapassar a norma que define o normal momentâneo, a possibilidade de tolerar infrações à norma habitual e de instituir novas normas em situações novas". Dentro da luta diária pela saúde, o alto índice de adoecimento da classe também evidencia o alerta de que existe algo na normalidade social/sociabilidade que não cabe no fazer singular/coletivo. A doença emerge num contexto em que o corpo transborda e suplica por novas normatividades que sejam ordenadas por modos de vida socialmente e politicamente qualificados.

\section{CONSIDERAÇÕES FINAIS}

A política deliberada de corte de bolsas ocorre no contexto atual do desenvolvimento do capitalismo, no qual há o predomínio de sua reprodução por meio da esfera financeira e do endividamento social. Os instrumentos jurídicos e políticos derivados da forma política do Estado, a forma-mercadoria, são mediadores privilegiados da ruptura com as políticas sociais nos momentos de crise do capital. Em tais momentos, os direitos e formas de proteção social são fragilizados e desmantelados progressivamente, ao mesmo tempo que tendem a ser justificados por seus protagonistas como responsabilidade fiscal e de gestão.

As repercussões para o bem-estar social são drásticas, e pudemos apontar para como enfraquecem a ciência enquanto conhecimento historicamente produzido que tenha relevância no enfrentamento das injustiças e desigualdades de nosso sistema social. As repercussões psicossociais e na saúde dos estudantes é notória, ao mesmo tempo em que neles acende a indignação e a consciência crítica. Muitos são abatidos pela depressão e por intenções muito preocupantes de até mesmo a retirada da vida, diante da desesperança que, para alguns, pode ser vivida como avassaladora. Longe de ser esse um problema circunscrito ao indivíduo, é, antes de tudo, indicador da crise social, ou como diria um clássico sociólogo, que jamais poderia ser estigmatizado de comunista pelos artífices do atual metabolismo da barbárie do capital, Durkheim (2005), como produtos de uma anomalia social.

Nesse mesmo sentido, fica evidenciado através das respostas das entrevistas que a bolsa, para além de um financiamento ou "salário" para estudante, integra, outrossim, um projeto acadêmico de uma ciência socialmente orientada para a formação integral e humana, não se limitando em subsidiar uma pesquisa ou outra, mas um projeto de Universidade produtora de conhecimento com função social no sentido do enfrentamento das desigualdades e iniquidades humanas de áreas de pesquisa; isto é, não se limita à formação acadêmica do estudante, pois se volta para a formação da consciência crítica e cidadania, que pode ser compreendida, tal como já mencionado, como mais um instrumento de formação humana integral ou omnilateral.

Sugerimos como atividade dialética de compreensão do texto aqui apresentado e de formação humana, a necessidade de refletir a função social da produção do conhecimento científico na contemporaneidade que as políticas aqui analisadas são produzidas. Nesse sentido, faz-se necessário refletir: no bojo do desenvolvimento de políticas de redução do financiamento de C\&T, e atentando-se para as possíveis repercussões, qual o preço que será pago em função do esvaziamento da valorização da produção de conhecimento que promovam emancipação e progressão da vida social digna? Qual o impacto do esvaziamento na vida de quem estuda e na sociedade? 


\section{THE DISMANTLING OF BRAZILIAN SCIENCE IN THE DELIBERATE CUTTING OF SCHOLARSHIPS: POLITICAL ASPECTS AND PSYCHOSOCIAL CONSEQUENCES FOR POSTGRADUATE STUDENTS}

ABSTRACT: This paper aims to present a comprehension of the national economic and political context based on assumptions of the Marxist field in order to analyze the process of science dismantling through instruments such as the ordinance No. 34 March 92020 proposed by CAPES. The stress dwells on the cutting of research scholarships destined to Brazilian postgraduate programs and students. The analyzed data consists on questionnaire replies from 72 students from the Federal University of Paraná (UFPR) in three major areas of knowledge (Formal; Natural and Social sciences). Results point to the predominance of a science denial policy whereby psychosocial processes are engendered from the economic effects and shutdowns of students' academic projects, to their health and subjectivity, with emphasis on stress and psychological suffering, or even depressive symptoms and even suicidal ideation.

KEYWORDS: Education. Education policy. Science funding. Psychosocial aspects. Ordinance 34/2020

\section{REFERÊNCIAS}

AZEVEDO, M. L. N. A integração dos sistemas de educação superior na Europa: de Roma a Bolonha ou da integração econômica à integração acadêmica. In: SILVA JR., João dos Reis; OLIVEIRA, João Ferreira; MANCEBO, Deise; (orgs.). Reforma universitária: dimensões e perspectivas. Campinas: Alínea, 2006.

BIANCHETTI, L. Os dilemas do coordenador de programa de pós-graduação: entre o burocráticoadministrativo e o acadêmico-pedagógico. In: BIANCHETTI, L; SGUISSARDI, V. Dilemas da pósgraduação em educação: gestão e avaliação. Campinas: Autores Associados, 2009.

BIANCHETTI, L.; MACHADO NETO, A. M. "Reféns da produtividade" sobre a produção do conhecimento, saúde dos pesquisadores e intecnsificação do trabalho na pós-graduação. $30^{a}$ Reunião da ANPED (Associação Nacional de Pós-Graduação e Pesquisa em Educação), anais de evento, grupo de trabalho 09, 2007. Disponível em < http://30reuniao.anped.org.br/trabalhos/GT09-3503--Int.pdf>. Acesso em: 29 de abr. de 2020.

BIANCHETTI, L.; VALLE, I. R. Produtivismo acadêmico e decorrências às condições de vida/ trabalho de pesquisadores brasileiros e europeus. Ensaio: aval. Pol. Públ. Educ., Rio de Janeiro, v.22, n. 82, p. 89-110, jan./mar. 2014.

CANGUILHEN, G. O normal e o patológico. Rio de Janeiro: Forense Universitária, 2002

DE FARIAS, A. M. L. Estatística Descritiva. Universidade Federal Fluminense. Instituto de Matemática e Estatística, Departamento de Estatística, 73 f., s/a. Disponível em: <http://www.professores.uff.br/ anafarias/pcontent/uploads/sites/32/2017/09/GET00170EstDesc.pdf $>$. Acesso em: 29 de abr. de 2020.

DEJOURS, C. A avaliação do trabalho submetida à prova do real: crítica aos fundamentos da avaliação. São Paulo: Blucher, Cadernos de TTO, 2008.

DEJOURS, C. A banalização da injustiça social. 7ed. Rio de Janeiro: Editora FGV, 2006.

DEJOURS, C. Para uma clínica da mediação entre psicanálise e política: a Psicodinâmica do Trabalho. In: LANCAMAN, Selma; SZNELWAR, Laerte Idal (orgs). Christophe Dejours: da psicopatologia à psicodinâmica do trabalho. Rio de Janeiro: Fiocruz, 2004.

DEJOURS, C. (2012). Trabalho vivo (Tomos I). Brasília, DF: Paralelo 15.

DOMINGUES, E. Autoria em tempos de "produtivismo acadêmico". Psicologia em Estudo, Maringá, v. 18, n. 2, p. 195-198 abr./jun. 2013. Disponível em <http://www.scielo.br/pdf/pe/v18n2/a01v18n2. pdf>. Acesso em: 29 de abr. de 2020.

DRUCK, G. Globalização, Reestruturação Produtiva e Movimento Sindical. CADERNO CRH, Salvador, n.24/25, p.21-40, jan./dez. 1996.

DURKHEIM, É. O suicídio. São Paulo: Martin Claret, 2005.

FAJOSES, L. D. S. Sofrimento discente na graduação em psicologia. 2019, 42.f. Trabalho de Conclusão 
de Curso (Graduação em Psicologia) - Instituto de Ciências Humanas e Sociais, Universidade Federal Fluminense, Volta Redonda, 2019.

HARVEY, D. Condição pós moderna: uma pesquisa sobre as origens da mudança cultural. São Paulo: Edições Loyola, 1992.

LEFÈVRE, F.; LEFÈVRE, A. M. Depoimentos e discursos: uma proposta de análise em pesquisa social. Brasília: Liber Livros Editora, 2005.

LIMA, Suzana Carnez da Cruz. Coletivo de trabalho. In: VIEIRA Fernando de Oliveira (org). Dicionário Crítico de gestão e psicodinâmica do trabalho. Curitiba: Juruá, 2013.

MACÁRIO, E.; REIS, L. F. COVID 19: dívida pública e crise de financiamento de ciência e tecnologia no brasil. 2020 Disponível em: https://auditoriacidada.org.br/conteudo/covid-19-divida-publica-ecrise-de-financiamento-de-ciencia-e-tecnologia-no-brasil/. Acesso em: 05 abr. de 2020.

MANCEBO, D.; SANTORUM, K. M. T.; RIBEIRO, C. V. S.; et al. O trabalho na educação superior. Archivos Analíticos De Políticas Educativas / Education Policy Analysis Archives, v. 28, p. 6-24, 2020.

MANCEBO, D. Contemporaneidade e efeitos de subjetivação. In: BOCK, Ana Mercês Bahia (org). Psicologia e Compromisso Social, 2 ed. São Paulo: Cortez, 2009.

MASCARO, A. L. Estado e Forma Política. 1ªed. São Paulo: Boitempo, 2013.

MASSON, G. Materialismo histórico e dialético: uma discussão sobre as categorias centrais. Práxis Educativa, Ponta Grossa, PR, v. 2, n. 2, p. 105- 114, jul-dez. 2007. Disponível em: < https://www. revistas2.uepg.br/index.php/praxiseducativa/article/view/312/320>. Acesso em 23 de fev. de 2020.

COORDENAÇÃO DE APERFEIÇOAMENTO DE PESSOAL DE NÍVEL SUPERIOR - CAPES.

Portaria $N^{\circ}$ 34, de 9 de março de 2020. Dispõe sobre as condições para fomento a cursos de pós-graduação stricto sensu pela Diretoria de Programas e Bolsas no País da CAPES. Dispõe sobre as condições para fomento a cursos de pós-graduação stricto sensu pela Diretoria de Programas e Bolsas no País da CAPES. Diário Oficial da União, 18 de março de 2020.

SANTANA, A. C. M. A constituição do Estado Avaliativo e o aumento das avaliações externas: propagando um ensino desigual para todos. In: ROTHEN, J. C. SANTANA, A. Avaliação da educação: referências para uma primeira conversa. São Carlos: EdUFSCar, 2018.

SGUISSARDI, V; SILVA JÚNIOR, J. R. Trabalho intensificado nas federais: pós-graduação e produtivismo acadêmico. São Paulo: Xamã, 2009.

SILVA, E. P; LEITE, A. P. T; REIS. A. C. O sofrimento do universitário e suas relações com a dinâmica universitária. Farol - Revista De Estudos Organizacionais e Sociedade, 2019.

TREIN, E.; RODRIGUES, J. O mal estar na academia: produtivismo científico, o fetichismo do conhecimento-mercadoria. Revista Brasileira de Educação v. 16 n. 48 set.-dez. 2011.

VOSGERAU, D. S. R.; ORLANDO, E. A.; MEYER, P. Produtivismo e suas repercussões no desenvolvimento profissional de professores universitários. Educ. Soc., Campinas, v. $38, \mathrm{n}^{\mathrm{o}}$. 138 , p.231-247, jan.-mar., 2017. 